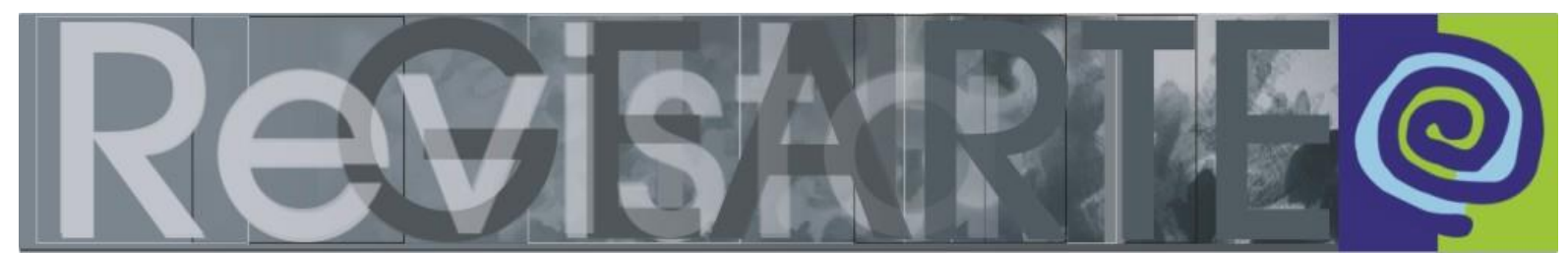

ISSN 2357-9854 | e-ISSN 2596-3198 (online)

\title{
Memórias e histórias do ensino de arte em Pernambuco
}

\author{
Maria Betânia e Silva \\ (Universidade Federal de Pernambuco - UFPE, Recife/PE, Brasil)
}

\begin{abstract}
RESUMO - Memórias e histórias do ensino de arte em Pernambuco - $O$ texto aborda memórias e histórias do ensino de arte em Pernambuco com base em narrativas construídas a partir dos resultados de duas pesquisas que objetivaram compreender o processo de inserção da arte no currículo escolar e que arte passou a ser ensinada na escola após esta inserção. O foco está centrado nas três décadas posteriores a segunda metade do século XX e o trabalho busca contribuir, também, para identificar permanências e rupturas nos processos educativos contemporâneos.
\end{abstract}

\section{PALVRAS-CHAVE}

Memórias. Histórias. Ensino de arte. Pernambuco.

RESUMEN - Memorias e historias de la Educación Artística en Pernambuco - El texto aborda memorias e historias de la Educación Artística en Pernambuco basados en narrativas construidas a partir de los resultados de dos investigaciones que tenían como objetivo comprender el proceso de inserción del arte en el currículo escolar y que el arte comenzó a enseñarse en la escuela después de esta inserción. El enfoque se centra en las tres décadas posteriores a la segunda mitad del siglo XX y el trabajo busca contribuir, también, a identificar permanencias y rupturas en los procesos educativos contemporáneos.

PALABRAS CLAVE

Memorias. Historias. Educación Artística. Pernambuco.

ABSTRACT - Memories and histories of art education in Pernambuco - The text addresses memories and histories of art education in Pernambuco based on narratives constructed from the results of two surveys that aimed to understand the process of inserting art in the school curriculum and that art started to be taught at school after this insertion. The focus is centered on the three decades after the second half of the 20th century and the work seeks to contribute, also, to identify permanences and ruptures in contemporary educational processes.

\section{KEYWORDS}

Memories. Histories. Art education. Pernambuco.

No prelúdio de sua obra Le Goff (2015) discorre sobre a incapacidade da humanidade na previsão exata do futuro, mas aponta sua necessidade em dominar seu longo passado. No entanto, nem prever e nem dominar com exatidão são ações possíveis quando tratamos de memórias e de histórias, pois suas narrativas são atravessadas por interesses carregados de subjetividades e, necessariamente, de lembranças e esquecimentos. Mergulham em contextos, 


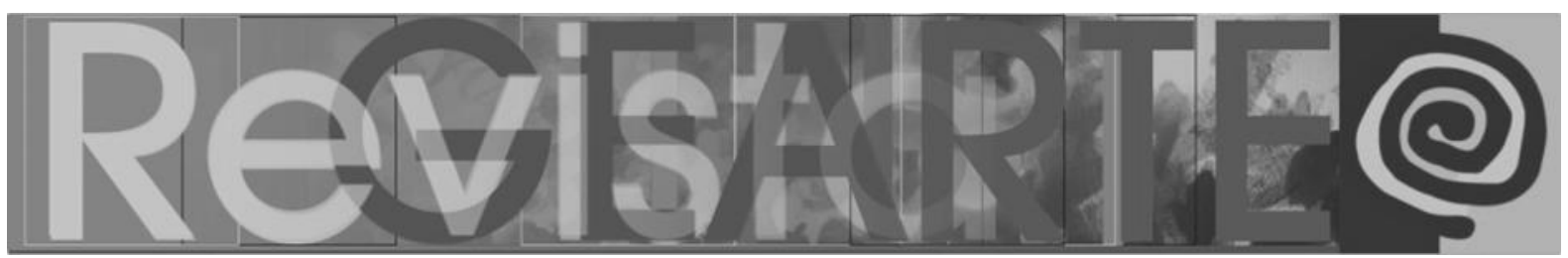

tempos, espaços específicos e acessam alguns dispositivos e disparadores para a construção de suas narrações.

Já dizia Ricoeur (2007, p. 26) que "a memória é passado". Esse pensamento se une ao tratamento que Candau (2012, p. 85) dá ao tempo afirmando que "pensar o tempo supõe classificá-lo, ordená-lo, datá-lo". Entendimento também trazido por Bosi (2003, p. 53), em seus estudos sobre memória, ao registrar que "a memória é, sim, um trabalho sobre o tempo, mas sobre o tempo vivido, conotado pela cultura e pelo indivíduo".

Diante disso, o texto que aqui apresento parte do olhar de uma pesquisadora sobre um tempo, lugar e contexto específicos, as três décadas que se seguiram após a segunda metade do século XX, especificamente, em Pernambuco. Reúne resultados de seus estudos de Mestrado e Doutorado realizados em duas universidades públicas brasileiras, em Programas de Pósgraduação em Educação, na linha de pesquisa sobre História da Educação. As pesquisas apresentaram os objetivos centrais na busca da compreensão do como se deu a inserção da arte no currículo escolar (SILVA, 2004) e que arte passou a ser ensinada na escola (SILVA, 2010).

A narrativa construída partiu do presente em direção ao passado para compreender um pouco do fio condutor de uma história do ensino de arte por meio de documentos possíveis de serem acessados e investigados no tempo destinado ao estudo. Entendo também a inexistência de uma única história, ensino ou arte, pois são múltiplas as histórias, os ensinos e as artes. Entretanto, os olhares multifacetados sobre um determinado tema de pesquisa permitem a ampliação e abertura do leque de compreensão e a identificação de elementos convergentes e divergentes que conduzem para a tessitura de novas relações.

Algumas inquietações provocadas no decorrer de nossa prática docente, quando ainda atuava na Educação Básica, foram o combustível para aprofundar como se deu parte da história de inserção da arte no currículo escolar. 


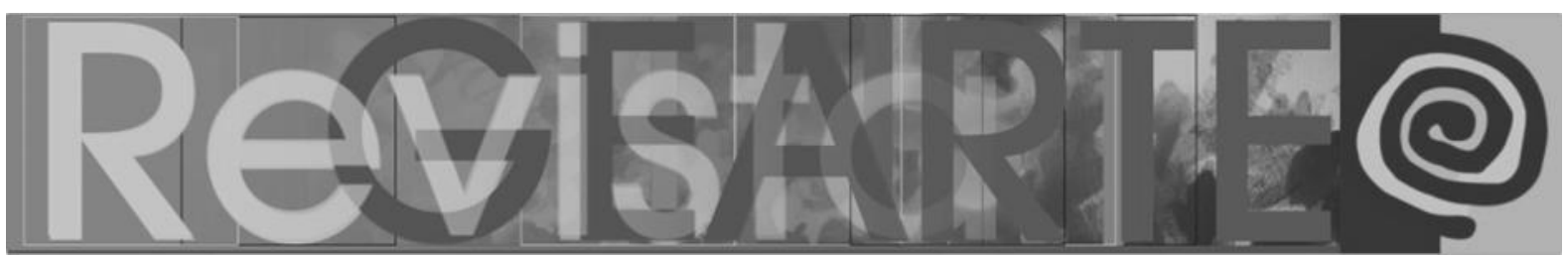

Nas narrativas identificadas, percebi que uma história do ensino de arte no Brasil esteve presente, inicialmente, no ensino superior voltado para a aristocracia da época e, sobretudo, para os que tinham talento ou dom inato, sendo reservado, assim, a uma pequena parcela da sociedade. Nas escolas primárias e secundárias o desenho geométrico fazia parte do currículo. No final do século XIX surgiu uma visão diferenciada, com Rui Barbosa, que pontuava a importância da arte no processo educativo e que dava força para os movimentos reivindicatórios de um espaço para a arte no currículo escolar brasileiro. Rui Barbosa recebeu influência norte-americana, pois parte de sua formação foi realizada nos Estados Unidos (SILVA, 2004).

No caso pernambucano, a importância da Reforma Carneiro Leão ${ }^{1}$ foi enfatizada também pela contribuição de Aníbal Bruno para colocar em prática a programação artística e cultural ali prevista. Na década de 1940 a Divisão de Extensão Cultural e Artística (DECA) desenvolveu um papel fundamental de orientação, promoção e divulgação das atividades artísticas no estado de Pernambuco. Essa instância centrou-se, sobretudo, no cuidado com a orientação continuada do professor no campo artístico promovendo, frequentemente, cursos, palestras e eventos artísticos que receberam destaque em meio à sociedade, como foi o caso dos Salões de Arte Infantil. Além disso, estabeleceu parcerias com a Escola de Belas Artes (EBA) e o Movimento Escolinhas de Arte (MEA). Até aquele momento a arte, oficialmente, não possuía um espaço obrigatório reservado no currículo escolar, mas percebi no percurso da pesquisa que ela já estava presente e ativa em vários processos educativos. A DECA não só contribuiu para que as atividades artísticas estivessem presentes e vivas na escola vinculando-as também à sociedade, como preocupou-se, fundamentalmente, com a orientação e atualização continuada do professor no campo artístico.

O Movimento Escolinhas de Arte, que surgiu contemporaneamente à DECA, teve um crescimento extraordinário em nível nacional atingindo também outros

Para um estudo sobre a Reforma Carneiro Leão em Pernambuco ver ARAÚJO (2002). 


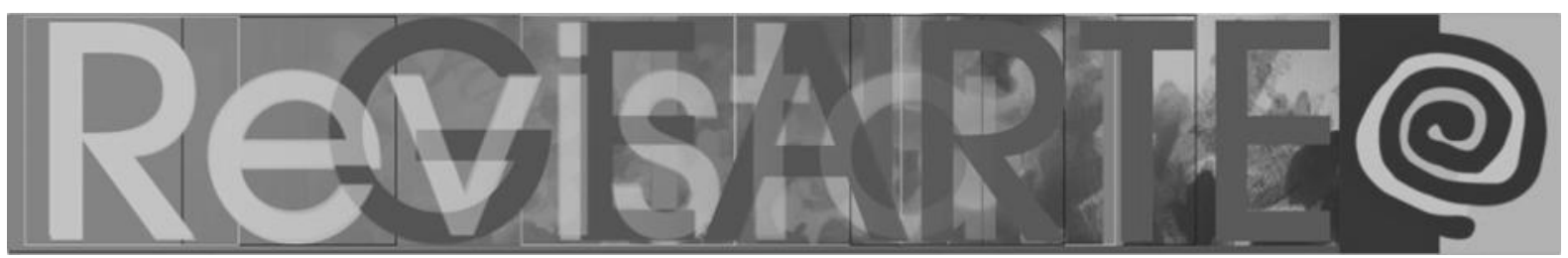

países. Foi uma nova forma de voltar o olhar para a criança e o adolescente, mas não só. Abriu espaço também para o adulto e para a formação de arte/educadores com os Cursos Intensivos de Arte Educação (CIAE), o que, até então, não se via na sociedade, exceto na Escola de Belas Artes. A Escolinha de Arte exerceu uma força considerável de norte a sul do Brasil tornando-se um espaço de organização, de encontro, de troca de ideias e experiências entre os arte/educadores. Silva (2004) afirma que a Escolinha de Arte estava conectada às discussões, ao que se produzia e desenvolvia em termos de arte na atualidade e, de modo especial, influenciou as autoridades educacionais da época despertando um olhar mais acurado à arte por parte do Estado, além de contribuir, consideravelmente, na concepção de arte que foi estabelecida no processo de inserção da arte no currículo escolar. Esta concepção se direcionou à livre-expressão, formação da personalidade, apreciação, gosto estético e criatividade.

Nos anos 1960 o Movimento de Cultura Popular (MCP)², também identificado em Recife, foi outro movimento que além do apoio político recebeu contribuições do comércio, da indústria e da imprensa. Esse movimento atingiu um número significativo de participantes de crianças a adultos tendo um desenvolvimento considerável na área artística, englobando não só a plástica, mas também a música, o teatro, o cinema, o artesanato. Foi um movimento que, literalmente, democratizou o acesso da população à arte, além de elevar o nível cultural e crítico das camadas populares e trouxe consigo a concepção da arte engajada, de expressão crítica e política voltada à transformação social. O estudo de Silva (2004) mostra que houve um movimento gradativo, crescente de observação, de articulação, de organização por parte de artistas, intelectuais e educadores que fizeram notar, que tornaram visível a importância da presença da

2 Para um estudo mais aprofundado de cada um dos lugares apresentados, vale destacar, sobre a Divisão de Extensão Cultural e Artística (DECA), Cavalcanti (1986) e Moser (1988); sobre o Movimento Escolinhas de Arte (MEA), Andrada (1997), Pedrosa (1993), Frange (2001) e Azevedo (2001); sobre a Escola de Belas Artes (EBA), Silva (1995), Marques (1988) e Pereira (2001). 


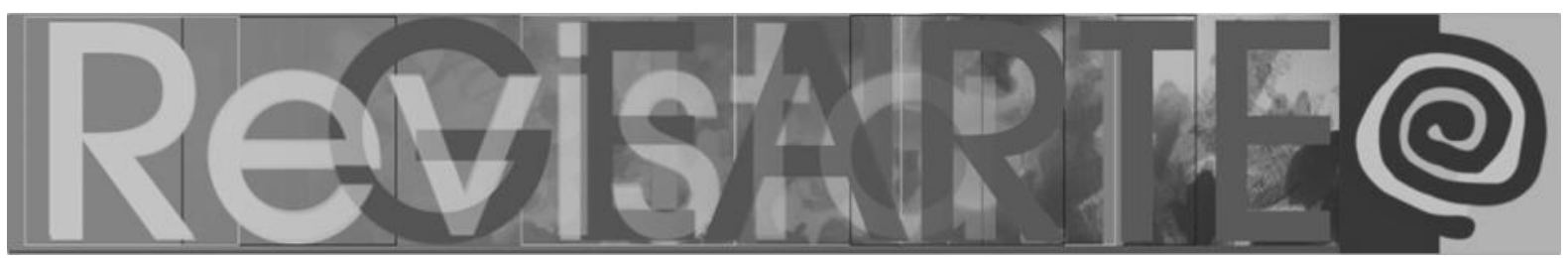

arte no processo educativo. Essa movimentação envolveu a sociedade e, sobretudo, despertou o interesse e o olhar nos meios políticos.

A década de 1970 foi marcada pela Reforma Educacional do Ensino de $1^{\circ}$ e 2o graus (BRASIL, 1971) que trouxe o símbolo de modernização e representou alguns avanços para a época, pois além da extensão obrigatória da escolaridade, generalizou o ensino profissional no nível médio ou $2^{\circ}$ grau. A nova reforma educacional trouxe consigo a concepção tecnicista na qual não importava a fundamentação teórica, a reflexão, o desenvolvimento do raciocínio críticoreflexivo, mas o fazer e, simplesmente, a técnica repetitiva. Entretanto, é possível afirmar que nem sempre o diálogo entre a teoria e a prática se efetiva. Teoricamente a lei apresentou avanços, mas na prática não houve e não se favoreceu uma estrutura técnica e humana adequada para torná-la efetivamente possível, como apresenta Silva (2004). Em linhas gerais, o conteúdo da reforma educacional trouxe influência norte-americana, mas a elaboração dos currículos e dos programas específicos foi realizada pelos educadores de cada estado, porém, com diretrizes pré-determinadas. Houve uma participação de educadores de norte a sul do país. No que se refere à arte, que recebeu um lugar específico e obrigatório no currículo e o título de Educação Artística, a sua presença não deixou de ser um avanço, no sentido de garantir um espaço para ela no currículo, democratizando o acesso ao ensino de arte, mas, por outro lado, encontrou-se a enorme lacuna nos recursos humanos específicos para a área.

Na sociedade brasileira, da época, não existia sequer cursos universitários que formassem professores de educação artística, nomenclatura que perdurou, pelo menos, até a década de 2000, o que deixou a desejar qualitativamente o ensino da nova disciplina. Outras lacunas foram identificadas na investigação de Silva (2004) como a ausência nas escolas públicas, em geral, de ambientes adequados para se trabalhar com o novo conhecimento, salas inapropriadas, excesso de alunos por turma, ausência de material, ausência bibliográfica específica nas escolas que auxiliassem o trabalho do professor, além da carga horária que para o professor cumpri-la precisava assumir no mínimo mais de 15 


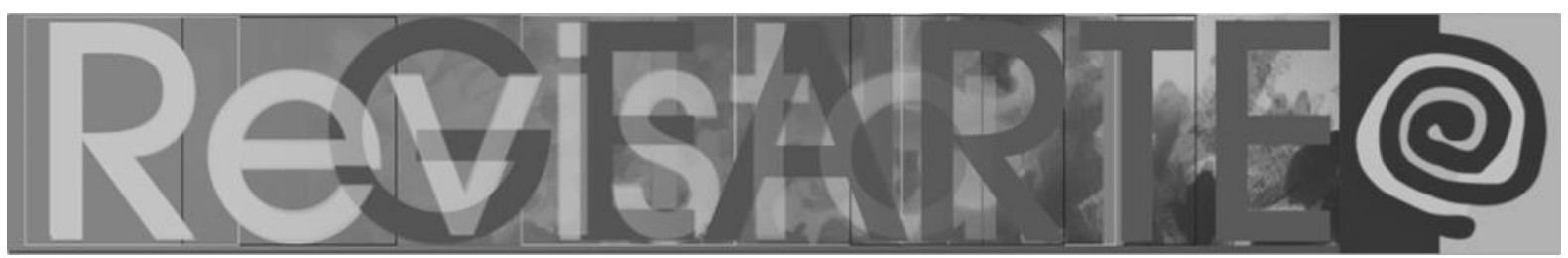

turmas de estudantes. Em suas conclusões a autora afirma que o Ministério da Educação e Cultura (MEC), do período, tinha consciência de todas essas lacunas, mas o que parece é que a intencionalidade estava centrada na desarticulação, na ausência de professores capacitados e formados na área artística e otimização da força de trabalho presente na escola, independente da necessidade de formação especializada. A lei deixou lacunas no tratamento dado ao professor para a área deixando aberto o ensino a qualquer profissional. O próprio MEC, quando elaborou os diversos pareceres ${ }^{3}$ durante a década de 1970 para esclarecimento do tratamento que deveria ser dado à disciplina de Educação Artística, deixou claro a não necessidade de um profissional específico para a área, fato que colaborou para a descaracterização da disciplina e acentuou o estigma de que a arte serve apenas para decoração do ambiente escolar e comemoração de datas festivas. Visava-se a despolitização ou repolitização no sentido de direcionar o ensino de arte ao patriotismo, ao nacionalismo com a comemoração das datas cívicas, dos personagens históricos, do folclore etc., desvirtuando completamente o que se desenvolvia em termos de arte na sociedade, sobretudo, nos movimentos e instâncias que trabalhavam mais diretamente com a arte. Foi aberto o espaço para qualquer profissional assumir a docência da disciplina. De um lado, não se corria o risco de contribuir na formação de indivíduos reflexivos, observadores, críticos por meio da arte, por outro lado o Estado brasileiro se ausentava da responsabilidade na formação de seu corpo docente especializado. Até então, se tinha visto em meio à sociedade o efeito que a arte causava na população como um todo através dos diversos movimentos e instâncias que desenvolveram o ensino, promoveram o acesso e divulgação da arte. Certamente, a presença de profissionais que desconheciam os fundamentos de um conhecimento específico favorecia a descaracterização da área, dificultava a articulação e organização dos profissionais e, consequentemente, favorecia o ensino de conteúdos diluídos e desarticulados.

3 Ver Parecer n853/71; Parecer n4833/75; Parecer CFE n540/77. Ver também Relatório que introduz o Parecer nำ540/77. 


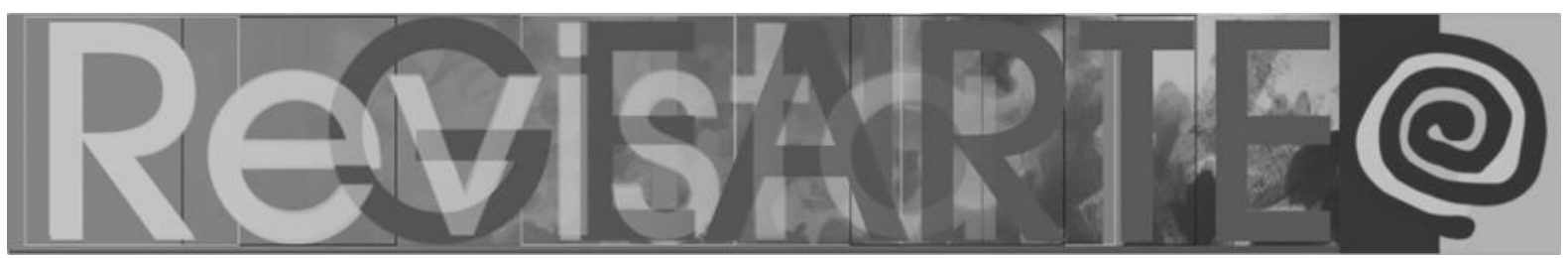

Ainda outros fatores destacados por Silva (2004) apresentam que, o foco no discurso de otimização da força de trabalho docente, maquiava a necessidade de investimento na educação brasileira seja no que diz respeito à formação docente, seja nos equipamentos educacionais. Pode-se dizer que o objetivo do novo regime foi alcançado, pois além de encerrar as atividades que se desenvolviam no campo artístico na sociedade, no caso pernambucano a DECA, o MCP e o próprio MEA que não foi encerrado, mas sofreu consequências, conseguiu diluir completamente o ensino e acesso ao conhecimento da arte por parte da população. No caso pernambucano, a ausência de profissionais da arte comprova-se com uma pesquisa realizada pela própria Secretaria de Educação do Estado, na década de 1980, período de redemocratização do país, que identificou a presença de apenas $14 \%$ dos profissionais que lecionavam a disciplina com formação artística, ou seja, $86 \%$ de todos os professores de Educação Artística do estado lecionavam a disciplina como complemento de carga horária. Este fato trouxe uma série de problemas, pois, além da ausência, em geral, dos conhecimentos específicos, filosóficos, metodológicos e psicológicos da arte impedia o acesso dos arte/educadores ao sistema público, uma vez que nos concursos públicos o número de vagas para a área era/é extremamente reduzido, pois burocraticamente o quadro está completo porque o espaço está preenchido por diversos outros profissionais, de diversas outras áreas. Problemas que se mantêm em muitos estados brasileiros.

Outra inquietação diz respeito à ausência do conteúdo programático. Durante a elaboração dos programas das diversas disciplinas redigiu-se um documento chamado Proposta Curricular (PERNAMBUCO, 1974). Este documento, elaborado com o objetivo de pontuar os aspectos mais importantes que deveriam ser abordados no ensino da disciplina de arte, contém um rol de objetivos e um conjunto de técnicas para desenvolver atividades artísticas.

A tendência tecnicista imperava no período, portanto, não havia interesse em elaboração de conteúdos formais e fundamentações teóricas, em especial também, no campo da arte, embora a Proposta Curricular contemple aspectos 


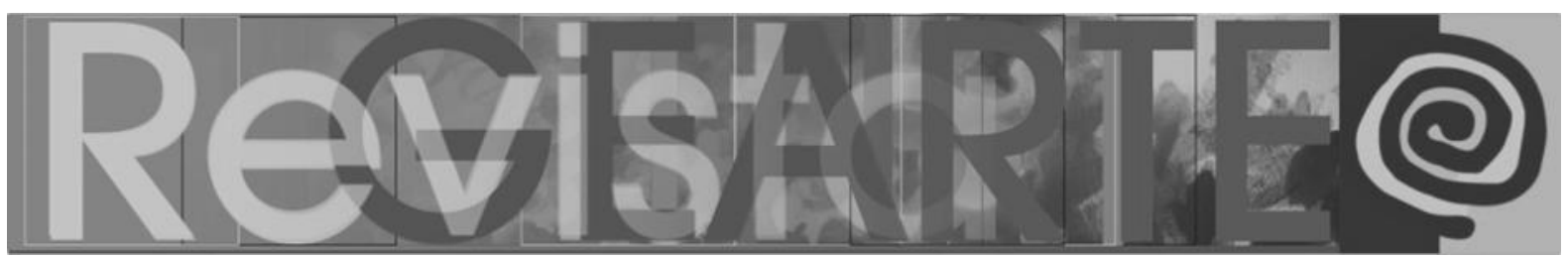

referentes ao MEA e aborde aspectos do desenvolvimento infantil trazidos por Piaget. Dessa forma, o campo permaneceu aberto para se ensinar qualquer coisa e se elaborar qualquer programa como atividades manuais, práticas do lar etc. Mas, como se podia elaborar um programa com conteúdos e linguagens específicas para a disciplina sem ter a necessária formação para desenvolver essas reflexões?

É interessante notar que durante a entrevista concedida para a pesquisa, Noemia Varela (2003) afirmou que:

(...) a gente pensava que ia realmente melhorar o nível do ensino de arte. Melhorou? Em certo sentido ele penetrou nos programas, faz parte, porque antigamente nem existia na escola arte da forma que a gente pensava, assim, na medida do possível de uma educação enriquecida e atualizada acrescentando experiências que elevassem o nível do professor. Isso não aconteceu até hoje.

Silva (2004) afirma ter sido uma conquista garantir um espaço para a arte no currículo escolar, após quase um século de reflexões, de tentativas dos educadores que precederam esta geração. Mas, inúmeras outras conquistas precisam ser alcançadas na instituição escolar e, em específico, no ensino de arte.

Buscando entender esse movimento de investigação sobre a inserção da arte no currículo escolar outras inquietações surgiram no percurso que possibilitaram levantar a seguinte questão: que arte passou a ser ensinada na escola após sua obrigatoriedade no currículo? A partir dela, outro estudo foi realizado e mergulhou em três instituições escolares públicas da cidade do Recife, que eram consideradas de referência no ensino secundário, nível de ensino da época até a Reforma Educacional de 1971 (BRASIL, 1971).

Entre outros aspectos, o estudo de Silva (2010) mostrou ser necessário conhecer que escolas eram essas, quem eram os professores que ensinavam arte, quem eram os alunos, que condições de trabalho havia nas escolas para o ensino de arte, que arte foi ensinada e como ela era ensinada. Assim, a pesquisa mostrou que os professores, que atuaram diretamente com o ensino de arte nas instituições 


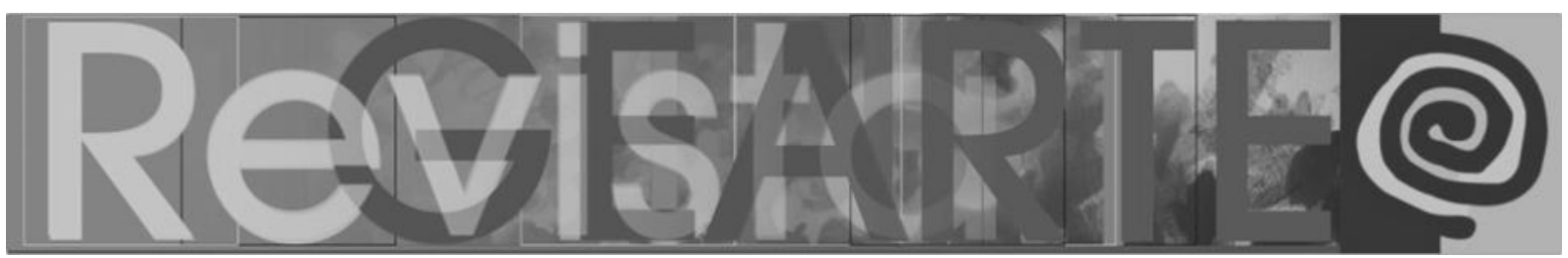

estudadas, vivenciaram em sua infância experiências artísticas na família e na escola que contribuíram em sua atuação profissional. As redes de relações construídas e estabelecidas em seus percursos individuais proporcionaram a abertura de caminhos e indicações para o desenvolvimento de uma atividade profissional relacionada ao campo da arte, especificamente, em sua docência. As diferentes atuações profissionais ampliaram o leque de conhecimento $e$ experiências que também contribuíram em seus trabalhos no cotidiano pedagógico.

Desse modo, a autora destaca que as experiências artísticas vividas no interior da família; a convivência com outras pessoas que participavam de formações no campo da música e usufruíam dos eventos culturais na cidade; o estímulo recebido na escola; a participação em grupo de teatro; a frequência a museus; apresentações teatrais; concertos e cinema foram alguns dos elementos que contribuíram para a formação artística pessoal dos professores. Além disso, a frequência em cursos, palestras, congressos e estágios promovidos por espaços de formação voltados ao professor e as experiências da prática cotidiana em sala de aula foram destacados como colaboradores na estruturação e na própria organização de seus trabalhos na docência em arte.

Embora a plasticidade da vida tenha direcionado os caminhos para uma atividade diferenciada das expectativas profissionais de origem, a formação adquirida, ao longo das trajetórias dos professores e a abertura da legislação oficial, facilitou a definição da docência em arte. A busca de materiais como revistas, livros, jornais que contribuíssem para organizar as suas práticas pedagógicas também foi apresentada como uma atividade constante. Dificuldades vividas e enfrentadas no cotidiano da carreira profissional foram destacadas, mas também intensos momentos de alegria, orgulho, realização e satisfação serviram de estímulo para permanecer e dar continuidade ao trabalho docente.

Mesmo com formações diferenciadas, os professores, que assumiram a disciplina da arte nas escolas investigadas em Recife, buscaram, em seus 


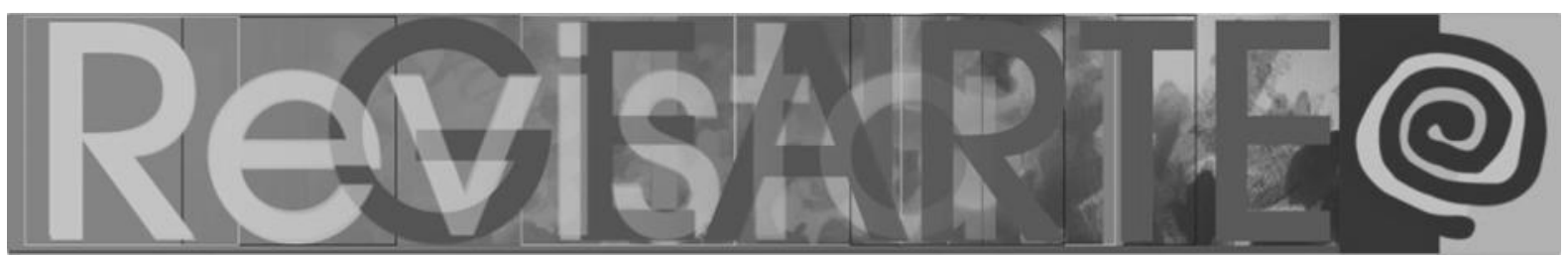

percursos de vida pessoal e profissional, além das experiências individuais, outros espaços de formação que contribuíram de forma significativa para a estruturação e organização de seus trabalhos pedagógicos. Todos esses elementos reforçam o dito por Tardif $(1991,2000,2005)$ ao tratar dos saberes docentes, entendendo-os como plurais.

Diante das dificuldades impostas ao trabalho pedagógico cotidiano, o professor explorou e inventou estratégias que possibilitassem uma aprendizagem prazerosa dos alunos. A invenção dessas estratégias utilizadas fazia parte do saber docente que se construía também através dos saberes da prática, das situações enfrentadas a cada dia em sua profissão.

O estudo apresenta também a diversidade de concepções de arte presente nos documentos oficiais, nos espaços de formação frequentados pelos professores e nos depoimentos dos professores, alunos e funcionários das escolas. Isso significa que cada escola possuía concepções diferenciadas de arte. Porém, no conjunto da pesquisa, o entendimento da arte como expressão e atividade foi apresentado como elemento comum entre as escolas. Em sua maioria, as concepções de arte dos alunos foram as mesmas de seus professores. Nesse sentido, posso dizer que se de um lado a escola é produtora de saberes, de outro ela também é reprodutora das concepções desses mesmos saberes que produz e veicula (SILVA, 2010).

Em duas instituições estudadas, o ensino de arte tinha, da mesma forma, o objetivo de produzir uma arte para ser vista e apreciada pelo público escolar e pelas personalidades que frequentavam as escolas seja nas festas, em datas comemorativas ou em outros eventos promovidos. A escola, ao apropriar-se da produção artística desenvolvida pelos alunos, utilizava-a como um marco diferencial do trabalho pedagógico que realizava. Em alguns casos, essa mesma situação ainda ocorre na contemporaneidade, em escolas da cidade do Recife, dado identificado nos acompanhamentos das experiências de Estágio Curricular, um dos componentes que tenho ministrado no Ensino Superior. 


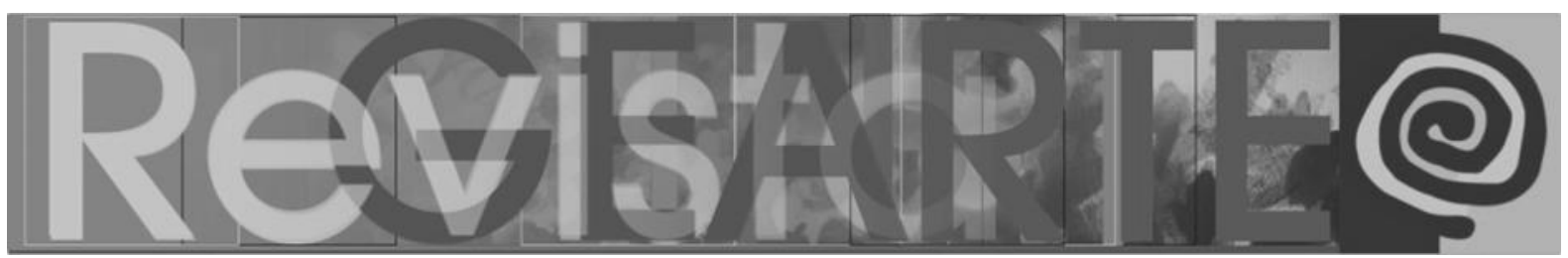

Em sua maioria, os alunos das instituições investigadas (SILVA, 2010) compunham o grupo seleto que atingia a educação secundária no Brasil, pois as condições socioeconômicas de suas famílias possibilitavam a permanência e a frequência nas escolas sem a necessidade de, ainda na adolescência, entrar no mercado de trabalho para manter-se e contribuir com a renda familiar.

O quantitativo de alunos por escolas e por salas de aula foi bastante diferenciado nas três instituições. Em uma delas, o grande número de alunos por sala foi uma das dificuldades apresentadas para o envolvimento de todos nas atividades planejadas pelo professor. Já em outra instituição pesquisada, o número de alunos, apresentado como satisfatório, possibilitava o acompanhamento individual dos mesmos, além de permitir a exploração de diversas experiências com os materiais e as técnicas viabilizando as atividades a serem realizadas.

O estudo também apontou que as aulas de arte eram consideradas por alguns alunos como um espaço de liberdade, menos rígido, sem realização de provas, mesmo com a exigência de refazer as atividades quando, na avaliação do professor, elas não atingiam um nível de qualidade esperada. As diversas experiências vivenciadas pelos alunos provocaram uma dinamicidade no espaço escolar e extraescolar. Muitos dos lugares observados e visitados durante a realização de atividades organizadas pelas escolas com os alunos corresponderam aos mesmos espaços que frequentaram os professores em suas trajetórias de formação. Esse dado me ajudou a perceber a influência das concepções de arte construídas pelos professores em suas vivências na formação de seus alunos.

Nas três escolas investigadas as metodologias de ensino de arte eram diversificadas, assim como as formas de veiculá-la no interior mesmo do espaço escolar. Além disso, a arte direcionada aos que tinham "dom, aptidão e talento" excluía os que não se encaixavam nesse perfil. A arte utilizada para eventos de comemoração de datas cívicas e folclóricas reforçava o projeto ditatorial de massificação da população, do "engrandecimento" do sistema de governo, de 


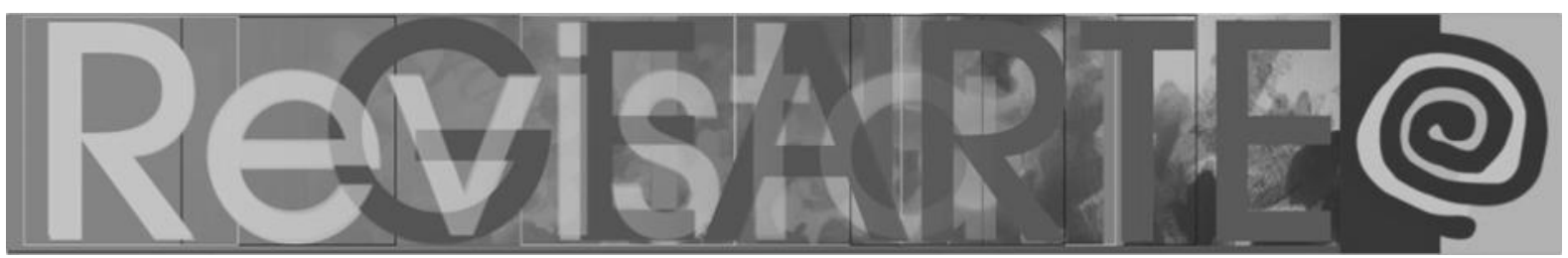

amenização da repressão que se vivia no período, de controle e distanciamento, pelo menos, da arte crítica e contestadora produzida e veiculada pelas vanguardas artísticas do período em outras instâncias sociais.

Para a escolarização da arte apresentada, o estudo mostra que a escola se configura como outro campo de produção da arte, outra arte, que é especificamente escolar, que não pode ser generalizada e nem uniformizada, pois cada escola possui suas singularidades e particularidades. Ao produzir um estilo escolar de arte, a escola foi evidenciada também como um lugar que se apropria de elementos dos diferentes saberes e das práticas sociais que circulam na sociedade e, principalmente, como construtora de seus próprios saberes. No entanto, o que sobressai é que inúmeros outros saberes produzidos pela escola são próprios dela mesma e para ela mesma. Esse corpus de saberes é estruturado, organizado, sistematizado para este lugar específico, para um tempo específico, para grupos de indivíduos específicos e somente nela é possível conhecê-lo, aprendê-lo e vivenciá-lo. Esse corpus de saberes está em constante dinâmica, portanto, não é estático e muito menos uniforme.

Nesse sentido, após o percurso de inserção da arte no currículo, a escola veiculou uma diversidade de compreensões, de ensinos, práticas e formas de avaliar a arte que atravessaram o tempo e contribuíram para a formação das gerações seguintes.

Esses estudos contribuem para conhecer, compreender e ampliar o entendimento sobre algumas narrativas de ensinos de arte do passado. Colaboram também para identificar permanências e rupturas nos processos educativos, bem como para a materialização de outras memórias e histórias.

\section{Referências}

ANDRADA, Maria Borges Ribeiro de. Escolinha de Arte do Brasil: a modernidade alcança a educação. Revista Arte e Ensaios. Resumo de Dissertação (Mestrado em História da Arte). Rio de Janeiro: UFRJ, 1997. 


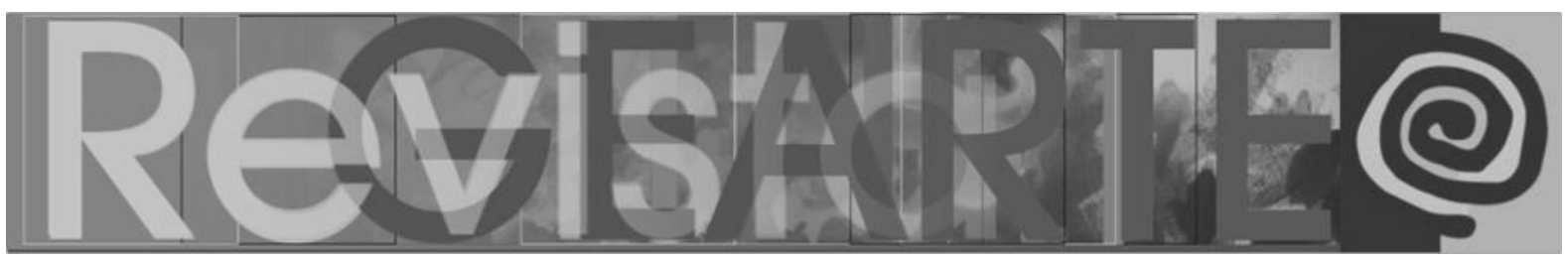

ARAÚJO, Cristina. A Escola Nova em Pernambuco: educação e modernidade. Recife: Fundação de Cultura Cidade do Recife, 2002.

AZEVEDO, Fernando Antônio Gonçalves de. Movimento Escolinhas de Arte: em cena memórias de Noemia Varela e Ana Mae Barbosa. Programa de Pós-Graduação em Artes/Universidade de São Paulo, 2001. Dissertação. (Mestrado em Artes).

BOSI, Ecléa. O tempo vivo da memória: ensaios de psicologia social. São Paulo: Ateliê editorial, 2003.

BRASIL. Ministério da Educação e Cultura. A Lei 5692 de 1971 e o Ensino de primeiro grau - Série Ensino Fundamental.

BRASIL. Parecer nำ53/71. MEC.

BRASIL. Parecer n4833/75. MEC.

BRASIL. Relatório que introduz o Parecer n540/77. MEC.

BRASIL. Parecer CFE $n^{\circ} 540 / 77$ - CE de $1^{\circ}$ e $2^{\circ}$ graus. Aprovado em 10/02/77 (Processo s/n). Sobre o tratamento a ser dado aos componentes curriculares previstos no art. $7^{\circ}$ da Lei no5692/71.

CANDAU, Joël. Memória e Identidade. São Paulo: Contexto, 2012.

CAVALCANTI, Zaida Maria Costa. DECA. Recife: Secretaria de Educação do Estado de Pernambuco, 1986.

FRANGE, Lucimar Bello. Noemia Varela e a Arte. Belo Horizonte: Ed. C/Arte, 2001.

LE GOFF, Jacques. A história deve ser dividida em pedaços? São Paulo: Ed. UNESP, 2015.

MARQUES, Norma de Oliveira. Escola de Bellas Artes de Pernambuco: aspectos de estudo histórico. 1988. Especialização em Artes Plásticas/Universidade Federal de Pernambuco, 1988. Monografia (Especialização em Artes Plásticas).

MOSER, Joana Siqueira. Salão Infantil de Arte: seu reflexo na educação pela arte. Especialização em Artes Plásticas/Universidade Federal de Pernambuco, 1988. Monografia (Especialização em Artes Plásticas).

PEDROSA, Sebastião Gomes. The influence of English art education upon brazilian art education from 1941. 1993. Programa de Pós-Graduação em Artes/ University of Central England in Birmingham, England, 1993. Tese. (Doutorado em Artes).

PEREIRA, Sonia Gomes. Academia Imperial de Belas Artes no Rio de Janeiro: revisão historiográfica e estado da questão. Revista Arte e Ensaios n. 8, p.73-83. Rio de Janeiro: UFRJ, 2001.

PERNAMBUCO. Secretaria de Educação e Cultura. Departamento de Ensino. Divisão de Ensino de $1^{\circ}$ e $2^{\circ}$ graus. Proposta Curricular - Ensino de 1ํo grau - Comunicação e Expressão, 1974.

RICOEUR, Paul. A memória, a história, o esquecimento. Campinas: Ed. da UNICAMP, 2007.

SILVA, Beatriz de Barros Melo e. A Pedagogia da Escola de Belas Artes do Recife: um olhar a mais. Programa de Pós-graduação em História/Universidade Federal de Pernambuco, 1995. Dissertação (Mestrado em História).

SILVA, Maria Betânia e. A inserção da arte no currículo escolar (Pernambuco, 1950-1980). Programa de Pós-Graduação em Educação/Universidade Federal de Pernambuco, 2004. Dissertação. (Mestrado em Educação).

SILVA, Maria Betânia e. Escolarizações da arte: dos anos 60 aos 80 do século XX (RecifePernambuco). Programa de Pós-Graduação em Educação/Universidade Federal de Minas Gerais, 2010. Tese. (Doutorado em Educação). 


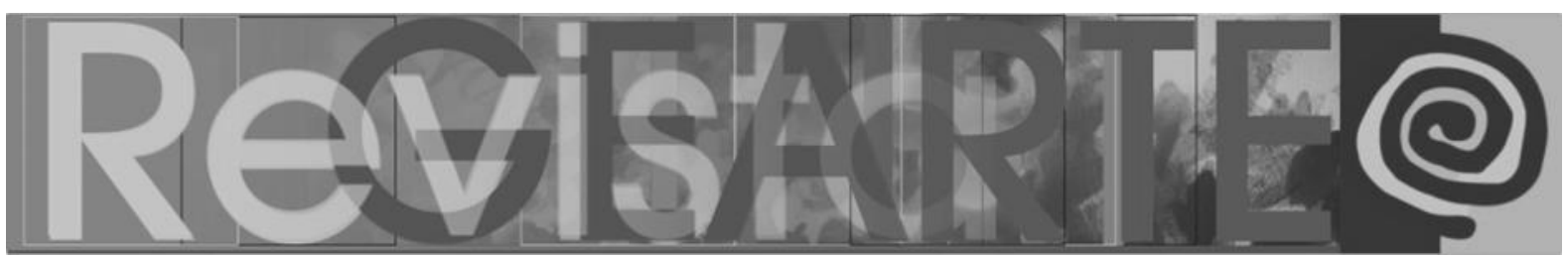

TARDIF, Maurice; LESSARD, Claude; LAHAYE, Louise. Os professores faces ao saber: esboço de uma problemática do saber docente. Teoria e Educação, 1991, n.4, p.215-233.

TARDIF, Maurice. Saberes profissionais dos professores e conhecimentos universitários. Revista Brasileira de Educação, 2000, n.13, p.5-24.

TARDIF, Maurice. Saberes docentes e formação profissional. Petrópolis: Vozes, 2005.

VARELA, Noemia. Entrevista concedida em 25.07.2003 na Escolinha de Arte do Recife.

\section{Maria Betânia e Silva}

Doutora em Educação pela Universidade Federal de Minas Gerais. Mestra em Educação pela Universidade Federal de Pernambuco. Graduada em Artes Plásticas - Licenciatura pela Universidade Federal de Pernambuco. É professora da Graduação e do Programa de PósGraduação em Artes Visuais da UFPE.

ORCID: https://orcid.org/0000-0002-2149-8982

E-mail: mbsppgav@gmail.com

Currículo: http://lattes.cnpq.br/0531466233320912

Recebido em 22 de maio de 2019 Aceito em 12 de dezembro de 2019 